\section{Withholding and with- drawing life-sustaining therapy in a Canadian intensive care unit}

Gordon G. Wood MD FRCPC, Edward Martin BSc
The purpose of this study was to document the rationale and procedures for withholding and withdrawing life-sustaining treatment in critically ill patients. A prospective observational study was conducted over 12 mo in a Canadian academic intensive care unit. Of the 110 intensive care unit patients who died during the study period, 71 (64.5\%) died after treatment was witheld or withdrawn. Compared with the other 39 patients who died despite full therapy, these patients were found to have a longer hospital and ICU stay, more organ systems failed, and a higher rate of malignancy. Intensivists rated poor prognosis for survival and poor quality of life should the patient survive as being the two most important factors when making a decision to withhold or withdraw treatment, while patient age and physical health prior to hospital admission were the two least important factors. There was a consistent approach to withdrawing therapy in 68 of the 71 patients. who had treatment either withheld or withdrawn. In these 68 patients, the first step was to write a do-not-resuscitate order, vasopressor drugs were then stopped and, lastly, the patient was weaned from mechanical ventilation and the trachea was extubated. The results of this study demonstrate that life-supporting treatment is commonly withdrawn in critically ill patients when continued therapy is thought to be unlikely to restore the patient to health.

Cette étude visait à examiner la logique et la pratique du refus et de l'arrêt du traitement vital chez les malades graves. Cette recherche prospective a été menée au Canada sur une période

Key words

ETHICS: do-not-resuscitate orders, life support withdrawal;

INTENSIVE CARE

From the Department of Anaesthesia, Queen's University, Kingston, Ontario, Canada.

The work was carried out in the Intensive Care Unit, Kingston General Hospital, Kingston, Ontario.

Address correspondence to: Dr. Gordon Wood, Department

of Anaesthesia, Douglas 2, Kingston General Hospital, 76

Stuart St., Kingston, Ontario, Canada K7L 2V7.

Accepted for publication 4th November, 1994. de 12 mois dans une unité universitaire de soins intensifs. Sur les 100 sujets décédés pendant cette période, 71 décédèrent après un refus ou un arrêt de traitement. Comparativement aux 39 autres patients qui sont morts malgré un traitement exhaustif, on a trouvé que ces patients avaient eu un séjour hospitalier et à l'unité de soins intensifs plus prolongé, que plus de systèmes avaient été défaillants et que la malignité était plus fréquente. Lorsquil s'agissait de prendre une décision, les intensivistes ont estimé que le pronostic vital défavorable et que la pauvre qualité de vie anticipée représentaient les deux facteurs les plus importants, alors que l'âge et l'état physique avant l'admission à lhôpital étaient les deux facteurs les moins importants. En face de la décision de cesser ou de s'abstenir de traiter, l'attitude était cohérente pour 68 des 71 patients. Pour ces 68 patients, le premier pas a été l'émission d'une ordonnance de ne pas réanimer, l'arrêt des vasopresseurs, et finalement, le sevrage du ventilateur et l'extubation de la trachée. Les résultats de cette étude démontrent que les thérapies de soutien vitales sont souvent supprimées chez les malades graves quand on croit que la continuation du traitement n'a pas de chance de ramener la santé.

The last half of the 20th century has seen rapid advances in medical technology. Critically ill patients treated in intensive care units (ICUs) have become especially dependent on recent innovations. This technology, while lifesaving for many, can only temporarily sustain the life of some patients and is unable to restore them to health. This has led to considerable financial costs as well as human suffering. Physicians are often required to withdraw life-sustaining treatment in hopelessly ill patients where continued treatment only serves to prolong the process of dying.

Various authors and professional organizations have published guidelines on withholding and withdrawing lifesustaining therapy. ${ }^{1-5}$ Much effort has been directed at developing methods to predict mortality in the critically ill to determine who will and will not benefit from continued intensive therapy. ${ }^{6-8}$ However, information regarding the actual process of withholding and withdrawing life-support is sparse. Two American reports examined 
this process ${ }^{9-10}$ but similar studies have not been conducted in Canada. The American experience may not be generalizable since medicine in Canada is practiced in a different financial and legal atmosphere. Because of this, we conducted a year-long observational study on the process of withholding and withdrawing lifesustaining therapy in a Canadian academic ICU.

The purpose of the study was to identify: (1) the proportion of patients who died in the ICU after treatment was withheld or withdrawn, (2) the patient characteristics which differentiated these patients from those who died despite full therapy, (3) the relative importance of factors which potentially influenced physicians decisions to withhold or withdraw treatment, and (4) the specific treatments which were withheld or withdrawn and the order in which this was done.

\section{Methods}

The study was conducted in the ICU of the Kingston General Hospital which is a 15-bed adult medical-surgical ICU affiliated with Queen's University. Institutional ethics approval was obtained before the start of the study.

\section{Study subjects}

All patients who died in the ICU during the 12-month (Feb. 1993 to Jan. 1994) study period were included. Some patients had treatment withheld or withdrawn in the ICU before being discharged to a general ward with the expectation that they will die there. These patients were also included if they died within seven days of ICU discharge.

\section{Definition of limiting therapy}

Subjects were divided into two groups; the limited therapy (LT) group comprised subjects who had treatment withheld or withdrawn before death, and the group who died despite full therapy (FT). Patients were included in the LT group only if withholding and withdrawing treatment had a critical influence on their subsequent clinical course. To be included in the LT group a subject had to meet each of the following criteria:

1 The decision to withhold or withdraw treatment must be made in consultation with the patient (or the patient's family in the case of an incompetent patient), the attending physician (patient's responsible physician prior to ICU admission), and the responsible intensivist, and all must agree to limit therapy.

2 The decision to limit treatment must be made before any acute deterioration of the patient and not during an active period of resuscitation solely because of the patient's failure to respond.

3 The patient would be expected to live for a minimum of $24 \mathrm{hr}$ if treatment was not withheld or withdrawn. (Patients were included in the FT group, not the LT group, when vasopressor drugs, antiarrhythmics, or respiratory support were withdrawn if it was judged they would have died within $24 \mathrm{hr}$ had these treatments been continued or increased.)

4 The patient is not brain dead when treatment is discontinued (brain death as defined by the Canadian Congress of Neurological Sciences). "

The attending intensivist was responsible for assigning patients to one of these two groups within $48 \mathrm{hr}$ of the subject's death based on the criteria above.

\section{Data collection}

Subject demographics were obtained in a blinded fashion by the investigators from the subject's chart. This information was obtained from all study subjects (those in the LT and FT groups) and included age, sex, presence of malignant disease, length of ICU stay, and length of hospital stay. The patient's physical health prior to hospitalization was graded based on the American Society of Anesthesiologists (ASA) classification. ${ }^{12}$ This was used to estimate the physical health of the patient prior to onset of the acute illness which resulted in ICU admission. The severity of illness on ICU admission was calculated using the Acute Physiology and Chronic Health Evaluation (APACHE II) score. ${ }^{13}$ The number of organ systems failed prior to the patient's death was determined using the criteria published by Knaus. ${ }^{6}$

The following additional information was obtained from the LT group only. A standardized questionnaire was completed by the responsible intensivist within 48 hr of the subject's death to rate the importance for that patient of seven variables (listed in Table II) which might be expected to have influenced the decision to withhold or withdraw life-sustaining therapy. A value of 1 to 5 was assigned to each variable (1: not important, 2 : minimally important, 3: moderately important, 4: very important, and 5: extremely important). The questionnaire also required the responsible intensivist to judge if the patient was competent to participate in the decision to limit treatment. If the patient was not competent, information the patient conveyed to friends or family members prior to ICU admission was used to determine the "patient's expressed wishes" in Table II. If no one knew the patient's wishes, the score was given as a 1 (not important). Also recorded was whether the subject had prepared formal written advance directives regarding medical care. The specific treatments which were withheld or withdrawn, the times when this was done, and the subsequent clinical course of the patient, was recorded for all LT subjects. This information was obtained from the chart by the investigators after the patient's death. 


\section{Statistics}

Statistical significance was set at $P<0.05$. Student's $t$ test was used to compare the differences in age and APACHE II score between the LT and FT group and the Chi-square was used when analyzing the sex distribution between groups and the difference in malignancy rate. The Mann-Whitney rank-sum test was used when comparing the means of the number of organ systems failed, the ICU and hospital length of stay, and the ASA status. Data are presented as the mean \pm SEM.

\section{Results}

During the 12-mo period, 1134 patients were admitted to the ICU and 110 subjects met the inclusion criteria for this study. All patients were assigned to the LT or FT groups within $48 \mathrm{hr}$ of death and all LT subjects had the standardized questionnaire completed within this time. Of the 110 subjects, $71(64.5 \%)$ had treatment limited and $39(35.5 \%)$ died despite full therapy.

There were no differences in the sex distribution, premorbid physical heath (ASA classification), or first day APACHE II score between the two groups (Table I). Patients in the LT group had longer ICU and hospital stays and more organ systems failed at the time of death in addition to a higher incidence of cancer, compared with the FT subjects. Thirteen patients in the LT group had only one organ system which had failed at the time treatment was withheld or withdrawn and in ten this was neurological failure due to severe brain injury.

Only one patient in the LT group had formal written advance directives. Only seven (10\%) of the LT patients were judged mentally competent to participate in the decision to limit therapy. Of the remaining $64 \mathrm{LT}$ patients, 38 had discussed with friends or family their wishes should they become hopelessly ill. The families of the other 26 patients did not know how the patient would feel regarding withholding or withdrawing treatment. Families initially refused to agree to withdraw lifesustaining therapy in three cases when the medical team presented this as the most appropriate action. Two accepted the recommendations within two days and the other after an additional week of treatment.

The mean score for the seven factors which potentially influenced the intensivist's decision to withhold or withdraw treatment are shown in Table II, in order of importance. When analyzed for all 71 LT subjects, "patient's expressed wishes to limit treatment" revealed a mean score of 2.8 which is the score listed in Table II. In response to this question, the responsible intensivist gave a score of 5 (extremely important) for all seven mentally competent patients. If the 38 incompetent patients whose families were aware of their wishes in the event of a serious illness were analyzed separately, the mean score was
TABLE I Comparison of patients who had limited therapy with those who died despite full therapy

\begin{tabular}{lllr}
\hline & $\begin{array}{l}\text { Limited therapy } \\
(n=71)\end{array}$ & $\begin{array}{l}\text { Full therapy } \\
(n=39)\end{array}$ & P value \\
\hline Age & $66.5 \pm 1.45$ & $59.4 \pm 3.4$ & 0.06 \\
Male/female & $42 / 29$ & $26 / 13$ & 0.44 \\
APACHE II score & $26.0 \pm 1.0$ & $26.3 \pm 2.0$ & 0.89 \\
ASA status & $2.8 \pm 0.09$ & $2.5 \pm 0.17$ & 0.39 \\
Organ systems failed & $2.6 \pm 0.13$ & $1.7 \pm 0.14$ & $<0.01$ \\
ICU stay (hr) & $183 \pm 19.7$ & $32 \pm 13.5$ & $<0.01$ \\
Hospital stay (hr) & $257 \pm 27$ & $156 \pm 61$ & $<0.01$ \\
Patients with cancer & 12 & 1 & $<0.05$ \\
\hline
\end{tabular}

Mean \pm SEM.

APACHE II, Acute Physiology and Chronic Health Evaluation.

TABLE II Reasons for limiting treatment as expressed by the attending intensivist (based on a score of 1 to 5 with $\mathrm{I}=$ not important, $2=$ minimally important, $3=$ moderately important, $4=$ very important, $5=$ extremely important)

\begin{tabular}{ll}
\hline Reason & Mean score \\
\hline Poor prognosis for survival & 4.8 \\
Poor quality of life should the patient survive & 4.2 \\
Presence of malignancy & 4.0 \\
Patient's expressed wishes to limit treatment & 2.8 \\
Patient's suffering should treatment continue & 2.6 \\
Physical health of the patient prior to hospital & \\
$\quad$ admission & 2.3 \\
Patient age & 2.0 \\
\hline
\end{tabular}

Only the 13 patients with documented cancer were used to calculate the score for "presence of malignancy."

4.1. There was a positive correlation ( $\mathrm{r}=0.53, P<$ $0.01)$ between the age of individual patients and the score given by the intensivist regarding the importance of "patient age" in the decision to limit treatment. There was also a positive correlation $(\mathrm{r}=0.51, P<0.01)$ between the ASA status (the measure of pre-morbid physical health) and the score given by the intensivist for "physical health of the patient prior to hospital admission."

There was a definite sequence to limiting treatment in all patients (Table III). The first act in every patient was to write a do-not-resuscitate (DNR) order ensuring that cardiopulmonary resuscitation would not be started if the patient deteriorated when further treatment was withdrawn. Withdrawing therapy in all but three of the 71 subjects followed a similar sequence. Thirty-one were supported with vasopressors and this was the first treatment to be withdrawn after which eight patients died without any further withdrawal. The remaining $60 \mathrm{pa}-$ tients had positive-pressure ventilation withdrawn and 20 died while the ventilator was being weaned (a mean of $3.4 \pm 1.1 \mathrm{hr}$ after the start of weaning). The remaining 40 patients died after tracheal extubation. The time of 
TABLE III Treatments withheld and withdrawn in the 71 limited therapy patients

\begin{tabular}{lcc}
\hline Treatment & Withheld & Withdrawn \\
\hline Cardiopulmonary resuscitation & 71 & - \\
Mechanical ventilation & 0 & 60 \\
Inotropes and vasopressors & 2 & 31 \\
Antibiotics & 1 & 14 \\
Dialysis & 7 & 5 \\
Intravenous fluids & 1 & 3 \\
Blood products & 2 & 2 \\
Nutrition & 0 & 16 \\
Oxygen & 0 & 13 \\
Surgery & 4 & - \\
\hline
\end{tabular}

death for these 40 subjects was $32.5 \pm 7.6 \mathrm{hr}$ after the wean from mechanical ventilation had started. Twentytwo of these patients were discharged from the ICU and died on a ward within the next seven days. (Two patients survived for longer than seven days after having treatment withdrawn in the ICU. They were not included in the study. Neither survived to be discharged from hospital.) The three patients who did not follow this pattern included one patient who died of renal failure after dialysis was withdrawn, one who died of gastrointenstinal bleeding after a decision was made to stop further blood transfusions, and one who died of renal failure when a decision was made not to start dialysis. This last patient was the only LT subject to have died after treatment was only withheld as opposed to also having had treatment withdrawn. Numerous patients had antibiotics, intravenous fluids, and nutrition withheld or withdrawn. These treatments were always withdrawn after the DNR order was written and when compared with the withdrawal of inotropes and mechanical ventilation, the limitation of these therapies was likely not as instrumental in the patient's subsequent clinical course.

Although the LT patients had active treatment withdrawn, they did not cease to receive medical care. Every effort was made to ensure patient comfort. Fifty-two of the 71 LT subjects were given morphine for comfort during the process of withdrawing mechanical ventilation with a dose of $11.5 \pm 1.6 \mathrm{mg} \cdot \mathrm{hr}^{-1}$.

\section{Discussion}

This study shows that the majority of patients who die in our ICU have had some form of life-sustaining treatment withdrawn before death. Despite the different financial and legal aspects of medical practice between the United States and Canada, two American studies have shown very similar results. In Smedira's study, ${ }^{9} 89$ of $198(45 \%)$ patients who died in their ICU had treatment withdrawn or withheld. This increased to $51 \%$ if the analysis included patients who had treatment limited in the
ICU but who died after discharge. Faber-Langendoen ${ }^{10}$ conducted a retrospective study and found that $74 \%$ of all hospital deaths and $65 \%$ of ICU deaths occurred after some form of therapy was withheld or withdrawn.

The study presented here is similar in design to Smedira's except that the assessment of factors which influence physician's decisions to limit treatment has been formalized. In addition, we have defined clearly what constitutes limiting treatment, something which was not done in the previous American studies. To some extent, almost every patient who dies in hospital has had some form of therapy withheld or withdrawn. For example, stopping an attempt to resuscitate a cardiac arrest patient after $30 \mathrm{~min}$ could be considered to be withdrawing treatment compared with continuing cardiopulmonary resuscitation for an hour. For this study we set strict criteria for the attending intensivist to use when deciding which patients had treatment withheld or withdrawn. As a result, the limited therapy group only included those patients in whom withholding or withdrawing treatment had, in the opinion of the intensivist, a considerable influence on the patient's subsequent clinical course. No attempt was made to validate independently the assigning of patients to the LT and FT group since this decision was made solely by the attending intensivist using the supplied guidelines. Irrespective of the differences in methodology, these studies demonstrate that it is common in North America to limit life-sustaining therapy in critically ill patients.

The limited therapy patients were similar to the full therapy patients with respect to their pre-morbid physical health (ASA status) and acuity of illness on presentation (APACHE II score) but had a longer ICU stay and more organ systems had failed at the time of death. This sug gests that it is the nature of the patient's course in the ICU, as opposed to their status on admission, which most influences decisions to withhold or withdraw treatment. Despite debate as to the definition of multiple organ system failure, studies have shown a strong association between the number of organ systems failed and hospital mortality in critically ill patients. Knaus ${ }^{6}$ (the definition of organ system failure used in this paper) showed that patients who had three or more organ systems which had failed for more than three days had a $98 \%$ mortality rate. The majority of patients in this study who had treatment limited despite involvement of only one organ system, had neurological failure. The willingness to limit treatment where brain injury is the sole problem may be due to several factors including the ability to predict outcome in traumatic ${ }^{14}$ and non-traumatic coma ${ }^{15,16}$ and the ability of physicians and families to comprehend the functional limitations facing those who survive with a severe neurological deficit.

When physicians were asked to rate the importance 
of factors influencing their decision to limit treatment, poor prognosis for survival and poor quality of life should the patient survive ranked highest. While patients should consider quality of life when deciding the limits of their own treatment, physicians should be cautious when making decisions about a perceived quality of life for an incompetent individual since doctors frequently rate quality of life worse than do the patients. ${ }^{17,18}$ The importance of the "patient's expressed wishes to limit treatment" depended on how the physician received this information. In the seven competent subjects it was rated very high (mean score of 5.0) since the physicians received this information directly from the patient. In the cases of incompetent patients who had previously made their wishes known through family or friends, it was also an important factor when deciding to limit treatment (mean score of 4.1). However, the mean score for all 71 LT subjects was only 2.8 since the 26 incompetent patients whose wishes were not known were included in the calculation. The overall result should be interpreted as a lack of knowledge of many patients' wishes, not a disregard for them. Only one patient in our study had prepared a written advance directive despite the recent attention paid to this process.

The presence of malignancy was important in the decision to limit treatment. This may be because the prognosis in many cancers is clearer than that of other critical illnesses. Table II demonstrates that age and physical health of subjects prior to hospitalization were the two least important factors in the decision to withhold or withdraw therapy for the limited therapy group as a whole. However, there was a positive correlation between the age of the patient and the score given for "patient age" as well as the ASA status and the score given for "physical health of the patient prior to hospital admission." Not surprisingly, this demonstrates that the age and premorbid health of patients become more important factors in intensivists' decisions to limit therapy in older patients and in those with pre-existing physical health problems, respectively.

This study reveals a consistent and orderly approach to withdrawing life-sustaining treatment. Only one patient died solely because therapy was withheld. When a decision was made to limit therapy, existing treatments were universally withdrawn. It is the policy in our ICU to admit all patients with a potentially reversible illness who have no previously stated wish to avoid advanced lifesupport measures. Few patients are admitted to the ICU having a DNR status on the ward. None of the subjects in this study had mechanical ventilation withheld since those who are not candidates for ventilation are seldom admitted to the ICU. Our approach is to supply full aggressive treatment until it is evident that the patient is not improving and further therapy is unlikely to restore the patient to health. At this point, after consultation with the family and appropriate physicians, a decision is made to limit therapy by actively withdrawing treatment. The first step in this process involves writing a DNR order after which inotropes are discontinued. Mechanical ventilation is then withdrawn in a stepwise manner. This process is often called "terminal weaning."19 Mechanical ventilation is gradually reduced while sedative drugs are used to prevent respiratory distress. Rapid extubation risks severe discomfort since there is no opportunity to adjust the sedation to the patient's needs. Morphine was the drug of choice and large doses were often required. We believe it is essential to make the patient comfortable during weaning even if the use of sedatives hastens death and this principle has been widely supported by others. ${ }^{4,5,20}$ It should be emphasized that withdrawal of treatment does not mean the cessation of all care and that all necessary steps are used to ensure patient comfort and dignity.

It is possible that the approach to withdrawing treatment was influenced by the intensivists' knowledge that the process was being investigated. It is also possible that the consistency of approach to withdrawing treatment is specific to the ICU in which the study occurred. All the intensivists work and communicate closely and they may have developed a common practice because of this. Therefore, caution should be used when generalizing these results to other centres.

Withholding, and to an even greater degree, withdrawing life-sustaining treatment is one of the most difficult but also one of the most important ethical issues in medicine. A few decades ago it was believed that a physician must do "everything" for a patient and the primary goal of medicine was to prevent death at all cost. ${ }^{21}$ More recently, physicians and the public have realized that the technology has limitations. A considerable proportion of critically ill patients cannot be restored to health and "everything" only serves to prolong their dying. The goal of any intervention should be to restore or maintain a patient's well being, and not have as its sole goal the prolongation of biological life. ${ }^{5}$ There have been numerous attempts to predict mortality at the time of ICU admission, but none are reliable enough to predict individual outcome and therefore cannot be used to make decisions regarding withdrawal of therapy. ${ }^{22}$ As a result, patients often receive maximal medical therapy initially and limiting treatment is only considered if they fail to improve. Fortunately, medical ethics is of the opinion that there is no difference between withdrawing life-support as compared to not having initiated it. ${ }^{21,23}$ This allows physicians to embark on a trial of treatment with the knowledge that therapy can be rationalized at any time depending on the patient's response. The professional organizations 
who have published guidelines on limiting treatment have supported this principle, ${ }^{4,5}$ However, studies have shown that not all physicians are as comfortable as the ethicists in this regard and some feel that while it may be appropriate to withhold treatment, it is not right to withdraw it. ${ }^{24,25}$ The concern is that this attitude may lead to patients being denied treatment "in order to avoid the more visible, emotionally challenging, and legally threatening process of withdrawing it."26

In summary, we have demonstrated that the majority of patients who die in our ICU do so after a decision has been made to withdraw life-sustaining treatment. These patients initially receive full treatment and have aggressive measures of life-support withdrawn when the responsible physicians think that continued therapy is unlikely to restore them to health.

\section{References}

1 Ruark JE, Raffin TA. Stanford Medical Centre Committee on Ethics. Initiating and withdrawing life support: principles and practice in adult medicine. N Engl J Med 1988; 318: $25-30$.

2 Luce JM, Raffin TA. Withholding and withdrawal of life support from critically ill patients. Chest 1988; 94: 621-6.

3 American College of Physicians Ethics Committee. American College of Physicians Ethics Manual. Part 2: The physician and society; research; life-sustaining treatment; other issues. Ann Intern Med 1989; 111: 327-35.

4 Task Force on Ethics of the Society of Critical Care Medicine. Consensus report on the ethics of foregoing lifesustaining treatments in the critically ill. Crit Care Med 1990; 18: 1435-9.

5 American Thoracic Society Bioethics Task Force. Withholding and withdrawing life-sustaining therapy. Am Rev Respir Dis 1991; 144: 726-31.

6 Knaus WA, Draper EA, Wagner DP, Zimmerman JE. Prognosis in acute organ-system failure. Ann Surg 1985; 202: 685-92

7 Lemeshow S, Teres D. Avrunin JS, Gage R. Refining intensive care unit outcome prediction by using changing probabilities of mortality. Crit Care Med 1988; 16: 470-7.

8 Lemeshow $S$, Teres $D$, Avrunin $J S$, Pastides $H$. A comparison of methods to predict mortality of intensive care unit patients. Crit Care Med 1987; 15: 715-22.

9 Smedira NG, Evans BH, Grais LS, et al. Withholding and withdrawing of life support from the critically ill. $\mathbf{N}$ Engl $\mathbf{J}$ Med 1990; 322: 309-15.

10 Faber-Langendoen K, Bartels DM. Process of forgoing life-sustaining treatment in a university hospital: an empirical study. Crit Care Med 1992; 20: 570-7.

11 Canadian Congress of Neurological Sciences. Guidelines for the diagnosis of brain death. Can J Neurol Sciences 1987; 14: 653-4.
12 American Society of Anesthesiologists. New classification of physical status. Anesthesiology 1963; 24: 111.

13 Knaus WA, Draper EA, Wagner DP, Zimmerman JE. APACHE II: A severity of disease classification system. Crit Care Med 1985; 13: 818-29.

14 Narayan $R K$, Greenberg $R P$, Miller JD, et al. Improved confidence of outcome prediction in severe head injury: a comparative analysis of the clinical examination, multimodality evoked potentials, CT scanning, and intracranial pressure. J Neurosurg 1981; 54: 751-62.

15 Longstreth WT Jr, Diehr P, Inui TS. Prediction of awakening after out-of-hospital cardiac arrest. N Engl J Med 1983; 308: 1378-82.

16 Levy DE, Bates D, Caronna JJ, et al. Prognosis in nontraumatic coma. Ann Intern Med 1981; 94: 293-301.

17 Uhlmann FR, Pearlman RA. Perceived quality of life and preferences for life-sustaining treatment in older adults. Arch Intern Med 1991; 151: 495-7.

18 Pearlmann RA, Jonsen $A$. The use of quality-of-life considerations in medical decision making. $\mathrm{J}$ Am Geriatr Soc 1985; 33: 344-52.

19 Grenvik $A$. 'Terminal weaning'; discontinuance of lifesupport therapy in the terminally ill patient (Editorial). Crit Care Med 1983; 11: 394-5.

20 Schneiderman $L J$, Spragg $R G$. Ethical decisions in discontinuing mechanical ventilation. N Engl J Med 1988; 318: 984-8.

21 Sprung $C L$. Changing attitudes and practices in foregoing life-sustaining treatments. JAMA 1990; 263: 2211-5.

22 Le Gall J, Lemeshow S. Do we need a new severity score? Crit Care Med 1991; 19: 857-8.

23 Jonsen AR, Seigler M, Winslaade WJ. Clinical Ethics. 3rd ed. New York: MacMillan Publishing, 1982.

24 Solomon MZ, O'Donnell L, Jennings B, et al. Decisions near the end of life: professional views on life-sustaining treatments. Public Health Policy Forum 1993; 83: 15-23.

25 Caralis $P V$, Hammond JS. Attitudes of medical students, housestaff, and faculty physicians toward euthanasia and termination of life-sustaining treatment. Crit Care Med 1992; 20: 683-90.

26 Singer $P$, Siegler $M$. Elective use of life-sustaining treatments in internal medicine. Adv Intern Med 1991; 36: 57-79. 